BULLETIN Bulletin hispanique

HISPANIQUE Université Michel de Montaigne Bordeaux

114-1 | 2012

Varia

Jacques Issorel, Fernando Villalón: la pica y la pluma

Espuela de Plata, Sevilla, 2011

Giovanni Caravaggi

\title{
CpenEdition
}

Journals

Édition électronique

URL : http://journals.openedition.org/bulletinhispanique/1959

DOI : 10.4000/bulletinhispanique. 1959

ISSN : $1775-3821$

Éditeur

Presses universitaires de Bordeaux

Édition imprimée

Date de publication : 1 juin 2012

Pagination : 486-487

ISBN : 978-2-86781-812-7

ISSN : 0007-4640

Référence électronique

Giovanni Caravaggi, « Jacques Issorel, Fernando Villalón: la pica y la pluma », Bulletin hispanique [En ligne], 114-1 | 2012, mis en ligne le 27 mai 2013, consulté le 23 septembre 2020. URL : http:// journals.openedition.org/bulletinhispanique/1959; DOI : https://doi.org/10.4000/bulletinhispanique. 1959

Ce document a été généré automatiquement le 23 septembre 2020

Tous droits réservés 


\section{Jacques Issorel, Fernando Villalón: la pica y la pluma}

Espuela de Plata, Sevilla, 2011

Giovanni Caravaggi

\section{RÉFÉRENCE}

Jacques Issorel, Fernando Villalón: la pica y la pluma. - Sevilla, Espuela de Plata, 2011, $206 \mathrm{p}$.

1 Cet ouvrage élégant et raffiné, publié sous le patronnage de la «Fundación Fernando Villalón » de Morón de la Frontera (Séville), représente le couronnement d'une longue série d'études et d'éditions critiques consacrées à ce poète andalou par Jacques Issorel, hispaniste très actif et engagé, spécialiste depuis une bonne vingtaine d'années de la personnalité et de l'œuvre de Fernando Villalón.

2 On doit à son activité sagace une thèse doctorale monumentale, soutenue à l'Université Paul Valéry de Montpellier et très tôt publiée, Fernando Villalón, ou la rébellion de l'automne. Un poète andalou de la génération de 1927 (Université de Perpignan, 1988); on lui doit aussi une série d'éditions critiques des œuvres littéraires de Villalón, progressivement enrichies par des mises au jour textuelles fondamentales, comme Poesías inéditas (Madrid, ed. Trieste, 1985), Obras. Poesía y Prosa (Madrid, ed. Trieste, 1987), "La Toriada " et autres poèmes tauriques (Perpignan, Mare Nostrum, 1990; ed. bilingue), Poesías completas (Madrid, Cátedra, 1998), ainsi que les Semblanzas de matadores (Patronato Federico García Lorca de la Diputación de Granada, 2002).

3 À tout cela il faut ajouter les nombreux articles, comptes rendus et autres contributions dont la liste complète serait trop longue; il suffit de remarquer ici que l'index onomastique de la bibliographie de Villalón, dont il est question plus bas, enregistre 35 références relatives à ses recherches.

4 Fruit mûr de cette longue activité exégétique, ce nouvel ouvrage se présente donc comme un « précis » captivant et essentiel de la vie et de l'œuvre de Fernando Villalón, 
composé de quatre grandes parties. Après une notice préliminaire (Palabras previas, p. 11-12), on trouve tout d'abord une chronologie très détaillée, qui fournit des données biographiques abondantes sur ce personnage. Lui font suite deux essais sur les deux entreprises qui ont occupé passionnément le poète andalou: l'élevage des taureaux de combats (Villalón, ganadero, p. 19-32) et la création poétique (Villalón, poète, p. 33-56). Le noyau de l'ouvrage est constitué par une ample anthologie des différents recueils poétiques de Villalón, qui avaient vu le jour dans les dernières années de sa vie ou étaient restés inédits au moment de sa mort (p.57-116); on trouve ensuite une bibliographie exhaustive, où sont rassemblées plus de 700 références.

Jacques Issorel ouvre ainsi aux lecteurs une perspective fascinante sur les ambitions et les déceptions d'un seigneur andalou qui rêvait de créer une race de taureaux fiers et combatifs, en tout dignes des meilleures traditions tauromachiques, et qui avait sacrifié presque toutes ses ressources pour obtenir cette incarnation prodigieuse de la vigueur naturelle, sans cesser de célébrer les grands mythes de sa terre fertile, malgré la faillite de ses tentatives et la ruine de son propre patrimoine familial.

6 Dans le premier recueil de Villalón, Andalucía la Baja, toutes les visions convergent vers l'exaltation d'une région bigarrée, de son passé mythique (les taureaux de Géryon) et historique (les Phéniciens, les Romains, les Rois Catholiques, les grandes conquêtes audelà de l'Océan), de son présent exubérant, de la joie de vivre et de la mélancolie de ses gens; tandis que $L a$ Toriada, dont le style se veut un hommage à Góngora l'année même du Tricentenaire, ne manque pas d'élans épiques. Cette longue silva de 521 vers exalte le triomphe du taureau dans une nature encore originelle, et son sacrifice par des "rustres toréadors", pour les lâches plaisirs d'une " populace tapageuse ». Les Romances del 800 interprètent avec une nostalgie touchante des épisodes historiques ou folkloriques du XIX siècle, et aussi, dans la section des Gacelas, les émotions d'un paysage séduisant. Parmi les poèmes inédits, on remarquera encore quelques textes suggestifs, comme les strophes visionnaires de Kaos, un poème cosmogonique complexe, ou les vers extravagants qui évoquent les amours entre une «camionnette Fiat » et « un Ford tout fraîchement peint ».

7 Cette brillante synthèse composée par Jacques Issorel nous permet ainsi de retrouver les aspects les plus attrayants de l'un des poètes les plus originaux de la Génération de 1927. 